\title{
Evaluation of association of fragility fracture and bone mineral density in Nepalese population
}

\author{
Amanullah MF, ${ }^{1 *}$ Shrestha BP, ${ }^{1}$ Khanal GP, ${ }^{1}$ Karna NK, ${ }^{1}$ Ansari $S,{ }^{2}$ Ahmad $K^{2}$ \\ ${ }^{I}$ Department of Orthopaedics and ${ }^{2}$ Department of Radiodiagnosis, \\ B.P. Koirala Institute of Health Sciences, Dharan, Nepal
}

* Corresponding Author:

Md. Farid Amanullah,

Department of Orthopaedics,

B.P. Koirala Institute of Health Sciences, Dharan, Nepal.

Email address: drfaridamanullah@rediffmail.com

\section{Citation}

Amanullah MF, Shrestha BP, Khanal GP, Karna NK, Ansari $S$, Ahmad K. Evaluation of association of fragility fracture and bone mineral density in Nepalese population. Nepal Journal of Medical Sciences 2013;2(2):130-4.

\begin{abstract}
Background: Fragility fractures are one of the major health problems. Many factors are associated with it some of which are modifiable and some are not. If we know the value of T-score at which fragility fracture occurs and associated factors responsible for fragility fracture than we will be able to control this burden to the society. The objective of this study is to determine association between fragility fracture and bone mineral density (BMD) using bone densitometry and to know the value of T-score at which fragility fracture occurs.
\end{abstract}

Methods: Patients presenting to B.P. Koirala Institute of Health Sciences with fragility fracture of distal end of radius, fracture around hip and vertebral fractures were included in the study to know the value of T-score at which fragility fracture occurs and their associated risk factor. Patients less than 50 years of age, high energy trauma fracture and pathological fractures were excluded from the study.

Results: We found that being multipara, smoking, alcohol consumption, post-hysterectomized patients and steroid intake had significant association with fragility fracture. There was no association with religion, geographic location, associated medical illness, age, sex, associated injury and site of injury.

Conclusion: The patients with risk factor for fragility fracture like smoking, alcohol consumption, multipara women, post-hysterectomized women and those who are on long term steroid therapy should undergo BMD test and the value at -3.254 are prone to fragility fracture and should be treated accordingly.

Keywords: Bone mineral densitometer; fragility fracture; osteoporosis; T-score

\section{Background:}

Osteoporosis is characterised by decrease in bone mass and increased susceptibility to fracture. Primary osteoporosis is defined as osteoporosis that occurs in an individ- ual who has no endocrinopathy or other disease state that would account for the changes in bone mass. The absolute number and percentage of persons who have osteoporosis are expected to increase because of the prolonged longev- 
ity of population in general. The risk of a fracture of the proximal part of the femur increases with age, especially in women who are more than fifty years old. Fractures of proximal part of the femur are associated with high rate of mortality and most persons who have sustained such a fracture never regain their previous level of function. ${ }^{1}$ In 1994, World Health Organization (WHO) defined osteoporosis as a condition in which the bone mineral density (BMD) is below $-2.5 \mathrm{SD}$ (standard deviation) or more below the mass for young healthy adults of the same race and gender-also referred to as a T-score of -2.5 . Those who fall at the lower end of the normal range (a negative T-score of $>1 \mathrm{SD}$ ) are defined as having low bone density and are considered to be at increased risk of osteoporosis. ${ }^{2}$ Dual energy X-ray absorptiometry (DXA, formerly DEXA) is considered the gold standard for the diagnosis of osteoporosis.

There exists a variety of factors which are responsible for osteoporosis. Some of them are modifiable (i.e. smoking habit, alcohol, etc) and some are not modifiable (i.e. age, sex, etc). The assessment of unconventional risk factors such as examining one's ability to rise from a chair without the use of arms to gauge proprioception, strength and coordination are simple, convenient and valuable in terms of predicting future risk. ${ }^{3}$ Early recognition and treatment of osteoporotic patients is crucial to the prevention of these fractures.

Since no study is available to deal the magnitude of the problem, this study was done to know the level of BMD for fragility fracture in Nepalese population. By this study the individuals who are prone to sustain fragility fracture can be identified and it will also help us to control fragility fracture by treating osteoporosis.

The objective of this study was to determine the association between bone mineral density and fragility fractures by using bone densitometer (DXA) and to know the value of T-score at which fragility fracture occurs.

Methods: The study was carried out on prospective basis over a period of 18 months (from December 2008 to July 2010). In this study, 50 patients with fragility fractures involving lower end of radius, vertebra and hip presenting to B. P. Koirala Institute of Health Sciences were included. Patients less than 50 years of age, high energy trauma fracture and pathological fractures were excluded from the study. After taking informed consent, history was taken followed by general systemic and local examination.

Several parameters were recorded in each patient like geographical location of the patient, occupation, ethnic group, religion, marital status, number of children, menopause, hysterectomy, history of smoking, any medical illness (rheumatoid arthritis, metabolic disorders, malignancies, etc.), alcohol intake, drugs (steroids therapy), injury pattern (mode, severity and site of injury) and BMD (T-score).

Plain radiographs of wrist, spine and pelvis including with both hips (all in antero-posterior and lateral views) were taken followed by DXA scan of the same regions on Osteocore 3 Visio Bone Densitometer to determine severity of osteoporosis. Data analysis was conducted using Epi-Info 2006 software. The value of T score and its means/medians were compared with continuous variables using t-test. We used multivariable analysis and their $\mathrm{P}$ values for association of multiple factors. After assessing the value of T-score at which fragility fracture occurs and their associated risk factor, all the patients received the definitive care for the fracture and osteoporosis.

\section{Results:}

In our study, out of 50 patients, $40(80 \%)$ patients were female and $10(20 \%)$ patients were male. 32 patients were of age $\leq 65$ years and 18 patients were of $>65$ years. Among 40 female patient, 18 (45\%) patients had $\leq 2$ numbers of children and $22(55 \%)$ had $>2$ numbers of children. According to geographical location, 17 (34\%) patients were from hillfoot areas, $22(44 \%)$ patients from hilly areas and $11(22 \%)$ patients were from terai areas. In this study 26 (52\%) patients were smoker and 24 (48\%) were non-smoker. There was history of medical illness in $6(12 \%)$ patients and 44 $(88 \%)$ patients had no history of any medical illness. 26 (52\%) patients were alcoholic and 24 (48\%) were non-alcoholic patients. $19(38 \%)$ patients were on steroid therapy and $31(62 \%)$ patients were not on steroid therapy. Out of 40 female patients, 7 (17.5\%) patients had history of hysterectomy and in $33(82.5 \%)$ patients hysterectomy was not done.

We did logistic regression analysis of all parameters which were statistically significant to know the strength of association and found that alcohol intake, smoking, hysterectomy, multiparity and steroid intake were strongly associated with fragility fractures. Female patients on the basis of number of children, multiparity and history of hysterectomy had significant P value. Significant P-value was also seen in alcoholics and in patients who were on steroid therapy for minimum of 2 years. Smokers had high T score. The significant T-score values between number of children, smokers, alcohol users, steroid therapy patients and hysterectomized patients are summarized in table 1 . 
Table 1: showing T-score and significant P-value.

\begin{tabular}{lccc}
\hline $\begin{array}{c}\text { Charac- } \\
\text { teristics }\end{array}$ & Categories & $\begin{array}{c}\text { T-score } \\
\text { (mean \& SD) }\end{array}$ & P-value \\
\hline Number of & $\leq 2$ & $-2.91 \pm 0.33$ & 0.00 \\
children & $>2$ & $-4.25 \pm 0.90$ & \\
Smoking & Smoker & $-4.29 \pm 0.89$ & 0.00 \\
& Non smoker & $-2.92 \pm 0.32$ & \\
& Alcohol & $-4.28 \pm 0.91$ & \\
Alcohol & consumer & & 0.00 \\
& Non & $-2.94 \pm 0.34$ & \\
& consumer & & \\
Steroid & User & $-4.47 \pm 0.97$ & 0.00 \\
& Not user & $-3.12 \pm 0.48$ & \\
& Done & $-3.23 \pm 0.68$ & \multirow{2}{*}{0.00} \\
Hysterectomy & Not done & $-3.38 \pm 0.56$ & \\
\hline
\end{tabular}

In our study, the P-value and T-score was found to be non-significant according to age group, males and females, medical illness present or not present, geographical location, occupation, religion and injury site. These non-significant values are summarized in table 2 .

Table 2: showing non-significant T-score and $P$ values.

\begin{tabular}{|c|c|c|c|}
\hline $\begin{array}{l}\text { Charac- } \\
\text { teristics }\end{array}$ & Categories & $\begin{array}{c}\text { T-score } \\
\text { (mean \& } \\
\text { SD) }\end{array}$ & P-value \\
\hline \multirow{2}{*}{ Age } & $\leq 65$ & $-3.65 \pm 1.01$ & \multirow{2}{*}{0.861} \\
\hline & $>65$ & $-3.60 \pm 0.91$ & \\
\hline \multirow{2}{*}{ Sex } & Male & $-3.74 \pm 1.00$ & \multirow{2}{*}{0.137} \\
\hline & Female & $-3.23 \pm 0.68$ & \\
\hline \multirow{3}{*}{$\begin{array}{l}\text { Geogra-Phical } \\
\text { Location }\end{array}$} & Foot & $-3.87 \pm 1.23$ & \multirow{3}{*}{0.330} \\
\hline & Hill & $-3.62 \pm 0.83$ & \\
\hline & Terai & $-3.30 \pm 0.68$ & \\
\hline \multirow{2}{*}{ Occupation } & Business & $-3.30 \pm 0.68$ & \multirow{2}{*}{0.178} \\
\hline & Housewife & $-3.74 \pm 1.02$ & \\
\hline \multirow{2}{*}{ Religion } & Hindu & $-3.65 \pm 0.99$ & \multirow{2}{*}{0.710} \\
\hline & Muslim & $-3.43 \pm 0.20$ & \\
\hline \multirow{2}{*}{ Medical Illness } & Present & $-3.61 \pm 0.48$ & \multirow{2}{*}{0.955} \\
\hline & Not present & $-3.64 \pm 1.01$ & \\
\hline \multirow{3}{*}{ Injury Site } & Around hip & $-3.81 \pm 1.15$ & \multirow{3}{*}{0.196} \\
\hline & Spine & $-3.26 \pm 0.66$ & \\
\hline & Distal end radius & $-3.78 \pm 0.91$ & \\
\hline
\end{tabular}

We found that BMD of -3.254 was associated with fragility fracture as compared to WHO criteria of -2.5; the possible reason could be that majority of our patients were residents of hilly areas, manual workers and hardworking, hence the bone is relatively stronger.

\section{Discussion:}

Osteoporosis is diagnosed when the bone mineral density is $\leq 2.5$ standard deviations below that of a young adult reference population. This is translated as a T-score. WHO has established the following diagnostic guidelines for osteoporosis: ${ }^{4}$

- T-score -1.0 or greater is normal.

- T-score between -1.0 and -2.5 is low bone mass (or osteopenia).

- T-score -2.5 or below is osteoporosis.

- T-score -2.5 or below with fragility fracture is severe or established osteoporosis.

Low trauma-fracture or fragility fracture is defined as one that occurs as a result of fall from a standing height, the term severe or established osteoporosis is used..$^{5}$ Osteoporotic fractures represent one of the major social challenges in terms of both illness and financial implications. However, unless preventive treatment is given to the people at increased risk of fractures this challenge will be very difficult to control.

Fractures represent the single most clinical event in patients with osteoporosis, yet remain under-predicted. As few premonitory systems for fractures exist, it is of critical importance that physicians effectively and efficiently identify individuals at increased fracture risk so that osteoporosis can be identified before it produces its complication in terms of breaking bones.

Singh et al $^{6}$ developed a useful system of grading osteoporosis (Table 3). Singh's Index is the change in the trabecular pattern of the upper end of femur can be used as an index for diagnosis and grading of osteoporosis. A highly significant correlation between this new roentgenographic method and Beck \& Nordin (1960) histological grading of iliac-crest biopsy specimen shows that the roentgenographic method reflects bone loss elsewhere in the skeleton fairly accurately.

Most people are under the misconception that they need not worry about osteoporosis until they are old. Nothing could be farther from the truth. More and more people in their early forties are falling victim to this debilitating disease in 
which bones become weakened and are more prone to fracture.

Table 3: Showing Singh's Index grading system.

\begin{tabular}{|c|c|}
\hline Grades & Characteristics \\
\hline 6 & $\begin{array}{l}\text { All the normal trabecular groups are visible and } \\
\text { the upper end of the femur seems to be com- } \\
\text { pletely occupied by cancellous bone. }\end{array}$ \\
\hline 5 & $\begin{array}{l}\text { The structure of principal tensile and principal } \\
\text { compressive trabeculae is accentuated. Ward } \\
\text { triangle appears prominent. }\end{array}$ \\
\hline 4 & $\begin{array}{l}\text { Principal tensile are markedly reduced in num- } \\
\text { ber but can still be traced from the lateral cortex } \\
\text { to the upper part of the femoral neck. }\end{array}$ \\
\hline 3 & $\begin{array}{l}\text { There is a break in the continuity of the principal } \\
\text { tensile trabeculae opposite the greater trochan- } \\
\text { ter. This grade indicates definite osteoporosis. }\end{array}$ \\
\hline 2 & $\begin{array}{l}\text { Only the principal compressive trabeculae } \\
\text { standout prominently; the others have been re- } \\
\text { sorbed more or less completely. }\end{array}$ \\
\hline 1 & $\begin{array}{l}\text { Even the principal compressive trabeculae are } \\
\text { markedly reduced in number and are no longer } \\
\text { prominent. }\end{array}$ \\
\hline
\end{tabular}

According to the National Osteoporosis Foundation of USA, by 2035 , India and China will have maximum number of osteoporotic persons in the world. ${ }^{7}$ If prompt preventive and corrective measures are not undertaken, we are heading for a handicapped and crippled elderly population in the current millennium. Prevention is better than cure and this cannot be over-emphasised with reference to osteoporosis. Early diagnosis is the key to prevent osteoporosis. Medical practitioners and patients alike are concerned with the understanding and optimum approach to the diagnosis, treatment and prevention of osteoporosis. The appropriate timing and proper use of agents, such as calcium, vitamin D, hormones, and bisphosphonates as well as the role of diet and exercise are issues that have generated major research efforts.

We studied 50 patients with fragility fracture and the mean value of $\mathrm{T}$ score is -3.254 at which fragility fracture occurred. Osteoporotic fractures were more common in multipara. It could be because of lack of appropriate nutritional support during pregnancy in our population. There is strong association of osteoporotic fracture with smoking because nicotine causes breakdown of estradiol. Similar study was done by Hoidrup $\mathrm{S}$ et al and found that tobacco smoking is an independent risk factor for hip fracture in men and women. ${ }^{8}$

In our study fragility fracture with low BMD also occurred in patients having high alcohol intake, which was also shown by Felson et $\mathrm{al}^{9}$ and Cawthon et al. ${ }^{10}$

We found that patients on long term steroid therapy were having low BMD. Similar study was done by Toogood JH et $\mathrm{al}^{11}$ and Kanis et $\mathrm{al}^{12}$ which showed that steroid therapy may adversely affect bone density in patients receiving long-term inhaled steroid therapy.

Simoes RD et al ${ }^{13}$ studied the effects of simple hysterectomy on bone loss and concluded that the bone densities of the hysterectomized women were lower than those of the normal ones. Similar result was found in our study. We did not find association of osteoporotic fracture with religion, age, sex, geographical location, occupation, associated medical illness and associated injury site.

We found that BMD of -3.254 was associated with fragility fracture as compared to WHO criteria of -2.5 BMD the possible reason could be majority of our patients are manual workers hence the bone is relatively stronger. The lifestyle modifications are required to prevent fall injuries such as: use of handrails on stairs and bathroom, to keep the floor clean $\&$ dry and to wear supportive, low heel shoes, etc. The patients with risk factor for fragility fracture like smoking, alcohol consumption, multipara women, post-hysterectomized women and those who are on long term steroid therapy should undergo BMD test and the value at -3.254 are prone to fragility fracture and should be treated accordingly. According to some researchers, a patient with a $\mathrm{T}$ score of $-1.5 \mathrm{SD}$ or lower should have a follow-up study in 2 years (if he or she is treated) to determine the efficacy of treatment. ${ }^{14,15}$

\section{Conclusion:}

The patients with risk factor for fragility fracture like smoking, alcohol consumption, multipara women, posthysterectomized women and those who are on long term steroid therapy should undergo BMD test and the value at -3.254 are prone to fragility fracture and should be treated accordingly.

\section{References:}

1. Lane JM, Riley E, Wirganowicz PZ. Osteoporosis: Diagnosis and Treatment. J Bone Joint Surg 1996;78:61830 . 
2. Karlsson MK, Gerdhem P, Ahlborg HG. The prevention of osteoporotic fractures. J Bone Joint Surg 2005;87:1320-7.

3. Johnston CC, Melton LJ, Lindsay R, Eddy DM. Clinical indication for bone mass measurement. A report from scientific advisory board of the National Osteoporotic Foundation. J Bone Miner Res 1989;4:1-28.

4. WHO Scientific Group on the Prevention and Management of Osteoporosis. Prevention and management of osteoporosis: report of a WHO scientific group. Geneva. 2003.

5. Report of a WHO Study Group. Assessment of fracture risk and its application to screening for postmenopausal osteoporosis. World Health Organization technical report series. 1994;843:1-129.

6. Singh M, Nagrath AR, Maini PS. Changes in trabecular pattern of the upper end of femur as an index of osteoporosis. J Bone Joint Surg. 1970;52:457-67.

7. Porthouse J, Birks YF, Torgerson DJ, et al. Risk factors for fracture in a UK population. Bone Min Res 1996;11:1935-42.

8. Hoidrup S, Prescott E, Sorensen Thorkild IA, et al. Tobacco smoking and risk of hip fracture in men and women. Int J Epidemiol 2000;29:253-9.
9. Felson DT, Kiel DP, Anderson JJ, et al. Alcohol consumption and hip fractures: the Framingham Study. Am J Epidemiol 1988;128:1102-10.

10. Cawthon PM, Harrison SL, Barrett-Connor E, et al. Alcohol intake and its relationship with bone mineral density, falls, and fracture risk in older men. J Am Geriatr Soc 2006;54:1649-57.

11. Toogood JH, Baskerville JC, Markov AE, et al. Bone mineral density and the risk of fracture in patients receiving long-term inhaled steroid therapy for asthma. J allergy clin immunol 1995;96:157-66.

12. Kanis JA, Johansson H, Oden A, et al. Meta-analysis of prior corticosteroid use and fracture risk. J Bone Miner Res. 2004;19:893-9.

13. Duraes Simoes R, Chada Baracat E, Szjenfeld VL,et al. Effects of simple hysterectomy on bone loss. Sao Paulo Med. J. 1995; 113:1012-5.

14. Cummings SR, Palermo L, Browner W, et al. Monitoring osteoporosis therapy with bone densitometry. JAMA. 2000; 283:1318-21.

15. Lenchik L, Watts N. Regression to the mean: What does it mean? J Clin Densitometry 2001;4:1-4. 